\title{
Acceptance in a Disaster Area: Process Technologies for Implementation Scientists
}

\author{
Tomohide Atsumi* \\ *Center for the Study of Communication-Design, Osaka University, Japan
}

(Received December 10, 2008 accepted June 21, 2009)

\begin{abstract}
This study introduces the process technology for implementation scientists to enter a disaster field and provides two case studies by focusing on the technology . First, its theoretical background is introduced. Second, it defines process technology as knowhow for implementation and practice, capacity building and social development for knowledge ownership. Third, it further elaborates on process technology for acceptance in a community. Then, it provides two cases of process technology use, one for the relief stage and the other for the revitalization phase. Finally, future views of this technology are discussed with emphasis placed on teaching methods for this technology.
\end{abstract}

Keyword: Process Technology, Implementation Science, Narrative-Design Science, Action Research, Community

\section{Introduction}

Obviously, survivors of disasters do not live simply for the purpose of research. They are not the objects of research, but possible partners. Therefore, when investigators want to conduct their own studies, they should reconsider the following questions before, during, and after the investigation: What purpose does this research serve? How does it contribute to the survivors before the researchers? Such reflective consciousness may lead investigators to achieve their aims with the survivors. To conduct studies with these considerations in mind, however, it is essential for disaster researchers to enter the disaster sites, and above all to be accepted in the community.

Scientists working on the implementation of findings (i.e., implementation scientists), not only with a human scienti f c background, but also with a natural scientific one, pursue collaborative practices with people (e.g., residents, practitioners, and researchers) in the disaster f eld. In other words, they conduct action research for the betterment of the feld. When they examine a disaster, they are supposed to go deeply into the disaster area to meet the survivors and start collaborative practices for the disaster relief, recovery, revitalization, and preparedness phases.

Disaster opens a community in that many rescue workers, medical doctors, nurses, of f cers, volunteers and researchers from outside go there and try to help the residents. Most of them are accustomed to dealing with survivors. However, while it is true that some make contact easily with survivors and begin collaboration over time, others do not establish any collaborative relationship with them at all. Of course, the former do possess some skills to meet and talk with the survivors. Kameda (2007) and his colleagues agreed to call such a skill a process technology , that is, know-how for implementation and practice, capacity building and social development for knowledge ownership. This study introduces the technology for implementation scientists to enter a disaster feld, and provides two case studies by focusing on the technol- 
ogy.

Previous studies on disaster have indicated the importance of gaining access to disaster fields. A recently published handbook on disaster research includes a chapter (Stallings, 2006) on methodological issues. It reviews many studies, classic and new, and examines timing, access, and the generalizability of methods used in field studies, survey research, and documentary research. For instance, if researchers enter a disaster site late, they are likely to lose contacts with key figures active immediately after the disaster, which may lead to the loss of access to precious information especially from formal or ganizations. However, even when researchers enter a disaster site at the right time, it is still unclear whether and how they become accepted in the feld.

Some research implicitly exemplifies the importance of acceptance in the field. For instance, Matsuda \& Okada (2006) developed a new systematic method of community diagnosis in a local community in Nagoya, Japan. They reported that a local nonprof $t$ organization had made close contacts with the residents in the community for a couple of years before the survey. In other words, without the long-term contacts between the community and the non-profit organization, this research would not have produced any reliable findings, or even survey questionnaires could not have been distributed in that community . As another example, researchers participated in a community for many years in order to examine its revitalization from a disaster (e.g., Kimura \& Takahashi, 2004). It was undoubtedly important for them to be accepted in the community . Otherwise, they would not have reported any suggestive fndings for future revitalizations. However, again, it is not clear ly described how they were accepted or what actions they took to be accepted.

Of course, it is insuf ficient for any researchers just to enter a disaster f eld and describe it, but instead the primary role of researchers is to produce theoretical discourses for the survivors because, as Lewin (1952) stated, there is nothing more practical than a good theory. Some researchers may stay in their laboratories or of fices to elaborate their theoretical considerations. Others may de f antly stay in the feld because they naively believe that theory can be found from data (Glaser \& Strauss, 1967). However , as Parker (2004) suggested, theories do not emerge from the field. On balance, implementation researchers are supposed to move back and forth between their libraries and the field(s). The process technology introduced here, therefore, does not cover the whole process of research, but is used to remove possible obstacles when entering the disaster feld.

The present study focuses on this technology . First, its theoretical background is introduced. Second, a process technology is elaborated for acceptance in a community. Third, it provides two cases, one for the relief stage and the other for the revitalization phase. Finally, future views of this technology (e.g., the teaching methods for this technology) are discussed.

\section{Theoretical Background}

Science is a part of our world of discourse, though it is exceptionally strong nowadays (Atsumi, 2008). In fact, besides scienti f c discourses, there are religious discourses, artistic performances, and so forth. It is hence ideal for us to take the whole discursive elements into account to support disaster survivors. However, realistically, scientists are supposed to approach the survivors from scientif c perspectives.

Atsumi (2007) categorized sciences into four categories (Table 1), allowing for the risk that any classification could invite false dichotomies and excessively polarized thinking. First, sciences are divided into nomothetic and narrative science. Nomothetic science includes natural sciences such as seismology . It attempts to determine the universal laws by testing hypotheses using the criterion of true or false. Narrative science, in contrast, contains social sciences such as sociology. It focuses on various discourses using the criterion of verisimilar or non-verisimilar.

Table 1. Categorization of Science

\begin{tabular}{|l|c|c|}
\hline & Epistemic Science & Design Science \\
\hline Nomothetic Science & Seismology & Engineering \\
\hline Narrative Science & Sociology & Group Dynamics \\
\hline
\end{tabular}

Another criterion is to divide sciences into epistemic and design sciences. Epistemic science is interested in the question, "What is it?" It first describes research objects as they are, explains them, controls them and predicts them. Once it is revealed 
what a particular phenomenon is, the epistemic scientists stop their investigation. Design science, on the other hand, focuses on the question, "What do you want to do?" It attempts to formulate a future plan by considering how it can be and how it should be. In other words, it designs a reality, practices it, and evaluates it.

The first cell of Table 1, nomothetic-epistemic science, corresponds to the so-called hard natural sciences. It is interested in f nding universal wisdom for global contexts because it is nomothetic. It is, therefore, based on logical empiricism in a broad sense. It typically compares control groups versus experimental groups, and tar get samples versus basic samples. These comparisons are made for universal under standing. Even if they focus on indigenous fndings, they ultimately try to use them to understand disaster in general. It is of course interested in understanding a phenomenon, but the implementation of the fnding does not receive primary focus because it is epistemic. It focuses, therefore, on how we can understand the reality, but does not pay much attention to how we can change it.

The second cell, narrative-epistemic science, corresponds to the humanities and most social sciences such as sociology. It is interested in indigenous wisdom and how people make sense of the reality through their interactions because it is a narrative science. It is, therefore, based on social constructionism in a broad sense. Even when it deals with universal patterns of conversation, for instance, it ultimately tries to utilize them to interpret the meanings in a par ticular context. It stops here, however, because it is epistemic. In other words, the implementation of the f nding does not receive primary attention.

The third cell of Table 1, nomothetic-design science, corresponds typically to engineering. It takes into account the universal law, e.g., physical law, because it is nomothetic. It is, therefore, based on logical empiricism in a broad sense. At the same time, however, it is also interested in implementing research f ndings in the real world because it is a design science. Therefore, it tries not only to understand the reality through the eyes of natural scientists, but also to change it.

Finally, the fourth cell, narrative-design science, corresponds to group dynamics (Atsumi, 2007). It is interested in indigenous wisdom, but for the local context per se. It is interested in how people make sense of the world through their interactions in the "here-and-now" because it is a narrative science with social constructionism in a broad sense. It focuses on dialogical features of everyday life in a particular context. It should be noted that it is also interested in implementing research findings in the real, that is, constructed, world because it is a design science. Therefore, it tries not only to understand the constructed reality, but also to change it.

Disaster research can be conducted in any cell of Table 1. However, when researchers attempt to contribute to the betterment of survivors' worlds where changes are expected, they are likely to conduct design scientific studies. In fact, that is why some engineers and researchers specialized in group dynamics have collaborated in action research for disaster survivors. However, it is now clear how different they are from each other. Engineers appreciate context-free f ndings and tend to be in favor of economy of explanation, so that if they submit a data set from a different context, it enthusiastically revises (or keeps) its old f ndings. In other words, fndings from a replication of an old research, for instance, may at best replace the old versions. Researchers of group dynamics, on the other hand, actually participate in local practices and attempt to illustrate and vivify the theory. A new ethnography does not replace an old one, but hopefully amplifies it. They occasionally change the reality collaboratively with their research partners in the field. Their activities resemble those of social workers, but they are interested not only in practice itself, but also in theoretical approaches toward changing the reality.

In sum, design sciences, either nomothetic or narrative, are interested in the betterment of disaster survivors' situation. Although engineering and group dynamics differ deeply from each other in their basic assumption of the world (i.e., nomothetic with logical empiricism versus narrative with social constructionism), they both need to work in actual disaster f elds. Process technology, therefore, is useful for both design type scientists.

\section{Process Technology for Acceptance in a Community}

Process technology originally drew attention through a project called Disaster Reduction Hyper - 
base (2006). Kameda (2007) and his international colleagues examined world-wide disaster research and practices not only from academic but also from practical perspectives, and widened the de f nition of technology: Technology is a set of rational means and knowledge pertinent to realizing specific objectives that have solid logical bases and stability. Then, they identified the implementation technology consisting of the following three core elements. First, implementation oriented technology is de f ned as products from modern research and development that are practiced under clear implementation strategies. Second, transferable indigenous knowledge is defined as the traditional art of disaster reduction that is indigenous to specific region(s) but having the potential to be applied to other regions and having time-tested reliability. Finally, process technology is defined as know-how for implementation and practice, capacity building and social development for knowledge ownership.

The project set the general criteria for all technologies and the particular criteria for each technology. The technologies, in general, should be understandable to users, implementable (i.e., usable, doable), and shown to be useful. Criteria for process technology are: (1) Placing emphasis on "practical use" of research, (2) A tested methodology with social, cultural, economic, ecological, and technical feasibilities, developed through an implementation/ testing process ensuring results in disaster reduction,

(3) Demonstrated stakeholders' participation and enhanced ownership of the process of results and lessons, (4) Amenable/adaptable to the local context, and with institutionalization potential, and (5) In-depth knowledge and insight gained through experience with disasters and mitigation.

When considering a community for disaster researchers to enter, f rst of all, they must realize that it is the "territory" of people who have lived there and the care of the residents (i.e., survivors) is the first priority. When they visit the area immediately after a disaster, they should respect, for instance, local rescue people. Concretely, by thanking them for allowing the researchers to participate in rescue and relief, they themselves should participate in and practice rescue and relief even though their academic background is not related to rescue or relief work.

To maintain the relationship with local people, investigators are supposed to visit the community frequently. However, they should not stick to conducting research. Of course, their purpose is to study particular issues, but this is a result of frequent visits. That is, they do not visit the area for research, but eventually return from the area with research results. They are recommended to meet community representatives and clarify their intention for the research, but should not start this immediately. They are supposed to communicate personally with local people, for instance, even by way of drinking with them socially.

When they reach the recovery stage, in addition to the issues above, researchers should be more sensitive to community people' s feelings than before because at that stage they have familiarized themselves with the community. In other words, they should be free from preoccupation or stereotypic opinions. Instead of talking to the residents, they should listen to them as they rest, for instance, at a designated smoking area. Of course, they should talk to the residents, but not direct them. It is usually recommended to observe human relationships among key persons and engage themselves in both formal and backroom meetings. When researchers wish to share their theories, they should do so at an appropriate timing.

If the research process takes much time, for instance, to reach its revitalization phase, researchers should stay in the field or find a substitute (e.g., a graduate student) for monitoring if forced to leave for a while. Because the residents at that stage can better understand who the researchers are, researchers can and should play their own roles depending on the situation: Be a scientist to the local people but not always. It is good to try and $\mathrm{f}$ nd a time and place to talk about the research concerns.

Obviously, these process technologies are very abstract. Therefore, it is worthwhile examining a couple of concrete examples.

\section{Case Study 1: Footbath for Survivors as a Process Technology}

The process technology introduced here is an example of the frst contact of people from outside of a community with its residents. A large earthquake hit the Noto Peninsula, Ishikawa prefecture on March 25, 2007. Local coastal villages were severely damaged and residents were evacuated from there by boat. As 
it was still early spring, it was especially dif f cult for elderly people to stay on the cold floors of shelters. University students from Niigata and Kobe formed the Chuetsu-Kobe Footbath Team for the evacuees in Noto and visited shelters to provide footbaths.

Footbaths have been provided at shelters after major disasters since the 1995 Kobe earthquake. It became a major activity of student volunteers from Osaka University not only at shelters, but also at temporary houses after the 2004 Chuetsu earthquake. Students from Kobe and Niigata learned its technique and, more importantly, the spirit and meaning of footbaths from those from Osaka University.

Footbaths relax people physically by placing their feet in warm water for 15 to 20 minutes; however, this is just a small part of their signi f cance. It is also a tool for establishing communication between survivors and volunteers. While taking footbaths, survivors and volunteers talk with each other . A volunteer may ask an elderly person how he or she was evacuated from the village while providing a footbath, whereas the elderly survivor may talk about his or her grandchildren to the volunteer. Without the footbath, it would be very dif ficult for student volunteers to start such communication because they are from the outside. It would also be very rare for local residents to have such conversation with strangers. However , especially after major life events such as disasters, people like to have someone to listen to their stories. Once they have an opportunity to talk and to be listened to, they are likely to feel more comfortable and relaxed. Of course, if volunteers detect any serious problems (e.g., mental health issues) through talking during the footbath, they then report the problems to local leaders. If volunteers do not detect any serious problems, conversation records are shared among volunteers and used for future relief activities.

It is true that footbaths are ineff cient in the sense that they must be given one at a time and a volunteer would provide them for only a few survivors per hour. However, volunteers have direct contact with survivors. They jointly spend time together and talk and listen to each other. This is the direct contact or physical touch that volunteers experienced in Kobe during the First Year of Disaster Volunteers, i.e., 1995. The direct contact is likely to lead volunteers to the status of contingency, under which they can adopt the reality as one alternative that would otherwise not have been chosen. In other words, by touching survivors directly, volunteers may feel not only that they are now helping, but also that they are helped. Such mode of thinking can restrain one-way support from volunteers to survivors, and promote mutual human interaction between them. Therefore, footbaths are a strong new tool of process technology for disaster relief by volunteers.

\section{Case Study 2: Staying in a Village for Revitalization with Process Technologies}

Although the footbath is administered for some time (e.g., Suwa, Atsumi, \& Seki, 2007), it is best suited to the first stage of contact with survivors. Here is another example of process technology that includes longitudinal relationships with local residents. On the $23^{\text {rd }}$ of October, 2004, a devastating series of earthquakes hit the mountainous area of Niigata prefecture. This major earthquake, called the Chuetsu Earthquake, affected small depopulated, rural villages in the mountainous area that is covered with deep snow in winter. Not only their lives and agricultural $\mathrm{f}$ elds, but also their traditional regional cultures were seriously damaged.

Shiodani is one such village in Ojiya city. It held 49 households before the earthquake, but 29 of them had to leave the village after the earthquake which killed three children in the village and crushed most of the houses. In the summer of 2007, 20 families f nally returned to the village after living in temporary houses in the city area. They are currently rebuilding their village lives with some volunteers including the author and his students. For instance, a series of workshops have been conducted since January 2008 to discuss issues for revitalization of the village, and rice f elds were cultivated with volunteers. Their traditional local network with neighborhood villages has also been expanded by the holding of a joint summer traditional dancing event.

What types of process technologies are required to collaborate with these local residents for an extended period of time? The most important technique is to work together with local residents on a daily basis. When researchers enter the community for the f rst time, it is obviously required to introduce themselves to the contact person in the village. Then, it is good to ask the local leader to introduce them to other 
residents. Because outside researchers are taught by the residents, they are supposed to be modest, and be open-minded to sharing both practical and academic aspirations and enthusiasm. When they fnd key persons in the area and develop a base for the activities, they should stay active in participating in the community's events (e.g., rice planting).

If researchers stay attentive to local residents, they usually find that the community is not indivisibly united. In other words, it is natural that the community is divided into sub-groups, according to attitudes toward various issues. Sometimes, there are some conf icts among them. Of course, it is simply impossible or inappropriate for the researchers to be indifferent to the conflicts because the more deeply they are involved in the community, the more often they are requested to express their own opinions. Researchers are advised not to stay neutral, but to face the residents with sincerity as individuals with their own opinions, ideas, and attitudes. Of course, they can be critical, but it should be productively critical.

As Section 2 of this article shows, researchers here are design scientists who would like to change the (constructed) reality through collaborative practice, so that they are supposed to have their own values and preferences either based on their scientif c knowledge or even on their own personal lives. To prepare, it is recommended that implementation scientists should talk and share common aspirations with local residents, study the areas thoroughly before and during the visit (e.g., visit the local library frequently), learn the local dialect and daily life patterns. It is always advised that investigators explain their theory and research in plain language (Atsumi, 2006). It takes time, but they should not be discouraged by a late progress.

\section{Future perspectives}

Obviously the process technologies listed in the sections above are limited to the particular locality . In fact, those technologies are based on the actual experiences of a series of long-term feldwork by the author who is both a researcher and an NPO staf $\mathrm{f}$ member. These are based on his own personal experiences.

The list of process technologies can be in f nite. Readers are supposed to examine the items listed in this technology here before, during, and after their research and practice. Remember, however, that the operation of these skills depends on the speci fc context of the particular disaster, and on the personality of the researcher. It changes, therefore, from case to case, and "Different strokes for different folks."

It is suggested that, at this point of time, once readers have studied these skills from this article with a couple of examples, they are strongly recommended to enter the actual f eld. In the feld, try to be creative and to improvise the skills they have studied here. If they are still at the learning stage (e.g., graduate students), they need to be trained in the f eld. Namely, it is best for them to follow an experienced researcher and ask him or her to take them to his/her own feld. This on-the-job-training (OJT), or in-the-f eld-training (IFT) should be effective. However, in future, further investigation is required on the methods for teaching this technology not only in the actual feld, but also in the classroom in advance of an actual disaster.

\section{References}

Atsumi, T. (2006). Tri-layer structure of presentations of collaborative practice: Cases from communicationdesign for disaster mitigation project. CommunicationDesign, 171-189 (in Japanese).

Atsumi, T. (2007). Aviation with Fraternal Twin Wings over the Asian Context: Using nomothetic epistemic and narrative design paradigms in social psychology. Asian Journal of Social Psychology, 10, 32-40.

Atsumi, T. (2008). Background and some examples of communication-design for disaster mitigation. Japanese Journal of Risk Analysis, 18(1), 45-51. (in Japanese).

Disaster Reduction Hyperbase (2006) accessible at http:// drh.edm.bosai.go.jp/

Glaser, B.G., \& Strauss, A.L. (1967). The discovery of grounded theory: Strategies for qualitative $r$ esearch. New York: Aldine.

Kameda, H. (2007). Def nition and criteria on IOT, PT, TIK, and criteria for DRH contents acceptance. EDM-NIED accessible at

. http://drh.edm.bosai.go.jp/common/documents/DRH_Criteria.pdf

Kimura, T., \& Takahashi, K. (2004). A study on the reconstruction process of dwellings after a volcanic disaster - a case study in Kamikoba district, Shimabara City . Journal of Japanese Society for Natural Disaster Sci- 
ence, 23(2), 229-244.

Lewin, K. (1952). Field theory in social science: Selected theoretical papers by Kurt Lewin. London: Tavistock.

Matsuda, Y., \& Okada, N. (2006). Community diagnosis for sustainable disaster preparedness. Journal of Natural Disaster Science, 28(1), 25-33.

Parker, I. (2004). Qualitative psychology. Buckingham: Open University Press.

Stallings, R.A. (2006). Methodological Issues. H. Rodriguez, E. L. Quarantelli, \& R. R. Dynes (eds.) Handbook of Disaster Research, New York: Springer, 55-82.

Suwa, K., Atsumi, T., \& Seki, Y. (2007). Disaster volunteers and two types of interest. Selected Papers by the International Society of Thir d Sector Research (On-line publication accessible at
http://www.istr.org/conferences/bangkok/WPVolume/Suwa. Koichi.pdf).

\section{Author's Note}

The essence of Case Study 1 and related concepts are registered in the Disaster Reduction Hyperbase under the title of "Social Skills required of researchers to ensure their acceptability in a disaster area", which is accessible at

http://drh.edm.bosai.go.jp/database/item/20ec1196 f6c906a5b0669959a351002f928a844f. Case Study 2 was partially supported by a special research grant from the president of the Japan Society for Natural Disaster Science, 2006-2008. 
